\title{
ENTREVISTA COM RODRIGO BRAGA
}

Interview with Rodrigo Braga

Entrevista con Rodrigo Braga

$>$ Claudia Tavares [Universidade do Estado do Rio de Janeiro, Brasil] *

Citação recomendada: TAVARES,

Claudia. Entrevista com Rodrigo Braga. Revista Poiésis,

Niterói, v. 22, n. 38 , p. 163-175, jul./dez. 2021. [https://doi. org/10.22409/poiesis.v22i38.49100]

Este documento é distribuído nos termos da licença Creative Commons Atribuição - NãoComercial 4.0 Internacional [CCBY-NC] (C) 2021

Claudia Tavares

(Submetido: 10/3/2021; Aceito: 13/5/2021;

Publicado: 7/7/2021)
RESUMO Entrevista com o artista Rodrigo Braga partindo de seu trabalho em vídeo intitulado Tônus. Para embasar a conversa, o trabalho Grande Budha, de Nelson Félix, e a ideia central do livro O Contrato Natural, de Michel Serres.

PALAVRAS-CHAVE arte, natureza, disputa, sujeito

ABSTRACT Interview with artist Rodrigo Braga based on his video work entitled Tólio. To support the conversation, the work Great Budha, by Nelson Félix, and the central idea of the book The Natural Contract, by Michel Serres.

KEY-WORDS art, nature, dispute, subject

RESUMEN Entrevista con el artista Rodrigo Braga basada en su trabajo en video titulado Tólio. Para apoyar la conversación, el trabajo Great Budha, de Nelson Félix, y la idea central del libro The Natural Contract, de Michel Serres.

PALAVRAS-CLAVE arte, naturaleza, disputa, sujeto

* Claudia Tavares é Doutora em Processos Artísticos Contemporâneos pelo Instituto de Artes da UERJ. E-mail: claudia@claudiatavares.com, ORCID: https://orcid.org/0000-0002-6724-3061 
A intenção dessa entrevista - realizada no apartamento do artista, no bairro de Santa Teresa, Rio de Janeiro, em 6 de março de 2018 - foi a de dialogar com o artista Rodrigo Braga sobre sua produção, que experimenta, tenciona e dialoga diretamente com forças da natureza. A conversa é norteada pela a ideia central do livro O Contrato Natural' ${ }^{1}$, do filósofo francês Michel Serres, que resumidamente sugere que os homens devem repensar a sua forma de interação com a natureza. Esse livro foi uma das balizas teóricas da minha tese, Um Jardim em Floresta, a natureza como sujeito ${ }^{2}$, onde a hipótese principal é da arte estabelecer uma relação de simbiose com a natureza, acrescentando assim um novo paradigma nas relações já estabelecidas de representação, contemplação e ou intervenção na natureza.

Esse paradigma propõe a interação entre arte e natureza, que convoca, além da visão, os outros sentidos do corpo a habitar essa relação. Propõe também a percepção do corpo da natureza, com sua fala própria, firmando-a como sujeito e não mais apenas como objeto.

As primeiras linhas escritas por Michel Serres no livro citado acima descrevem uma disputa entre dois inimigos que lutam num campo de areia movediça. O filósofo, inspirando-se na pintura de Goya, não deixa escapar que os dois lutadores se enfrentam sobre um pântano e, assim, quanto mais se movimentam mais se afundam. Parte da série de Pinturas Negras, Duelo a Garrotazos se refere à disputa politica como luta pelo poder entre os homens. Serres, no entanto, utiliza essa imagem para se referir ao momento em que nos encontramos enquanto humanidade em nossa relação com a Terra. A disputa entre os dois homens pintados, para ele, não se restringe à disputa no domínio específico entre os homens, mas sim entre humanidade e natureza. "A cada movimento, um buraco viscoso engole-os e ambos se enterram na lama gradualmente. A que ritmo? Isso depende da sua agressividade: na luta mais encarniçada, os movimentos mais vivos e secos aceleram o atolamento" [SERRES, 1990]. 


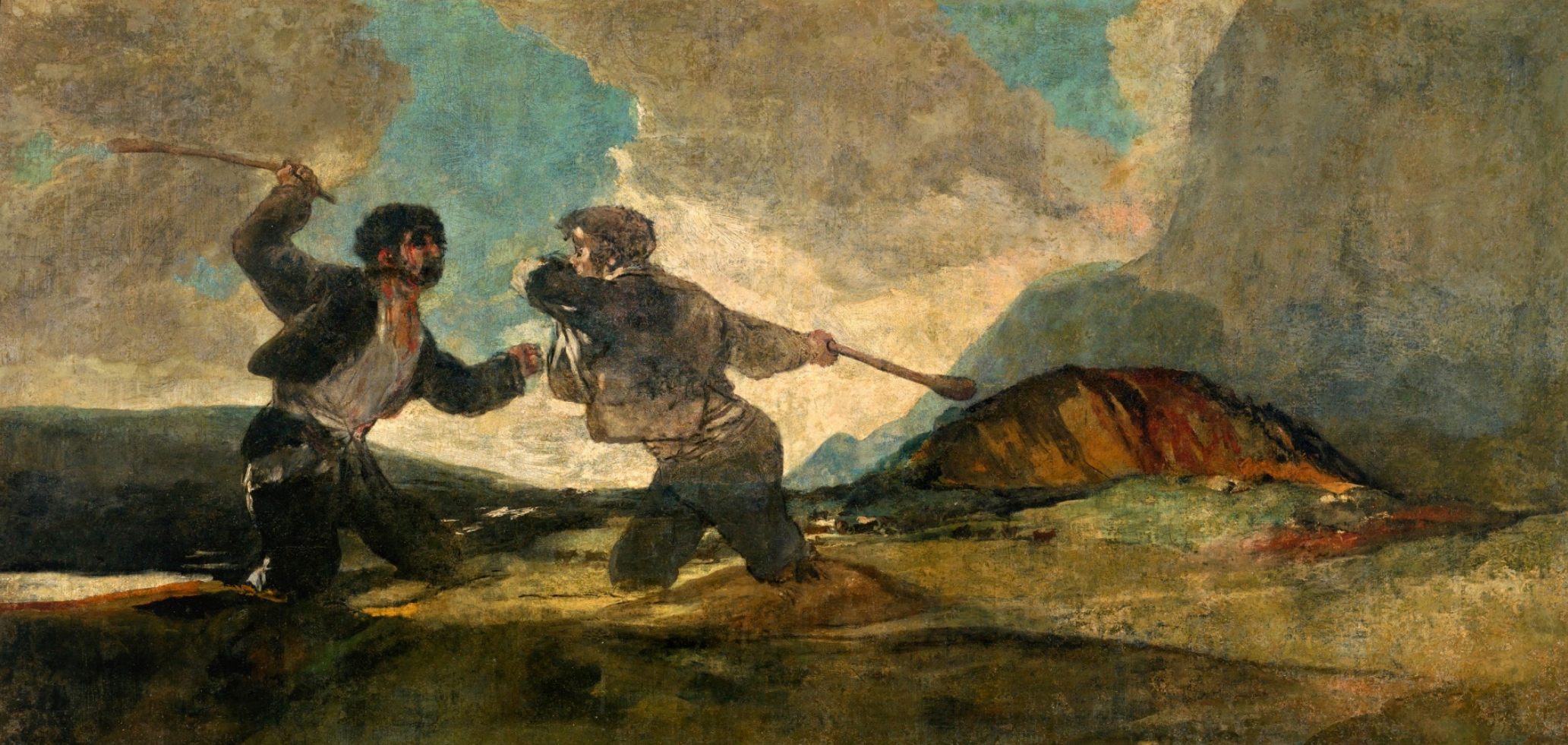

Fig. 1 - Francisco de Goya, Duelo a garrotazos, 1820. óleo sobre tela, $92 \times 130 \mathrm{~cm}$ Fonte: Acervo Museo del Prado

Chama a atenção para nós, espectadores, que ficamos de fora assistindo e apostando em um ou outro lutador, sem nos darmos conta do pântano. Fixamos nosso olhar nos homens e esquecemos de prestar atenção à natureza. "Em que areias movediças nos atolamos em conjunto, adversários ativos e espectadores perigosos?"[SERRES, 1990]. O autor pressupõe uma sociedade que se funda no paradigma da dominação antropocêntrica da natureza, apontando o primado da espécie humana sobre ela, que estabelece uma relação onde a natureza, com seus recursos naturais, é serva do homem. Seu pensamento, no entanto, vai muito além, nos provocando a pensar nas múltiplas crises contemporâneas que atravessamos, sejam elas ambiental, energética, alimentar, migratória, política, sanitária, militar e/ou econômica. E sem dizer explicitamente, entretanto, aponta que o conjunto de todas essas crises parece ter um mesmo ponto de partida: a situação de batalha entre humanidade e natureza. 
Não posso deixar de pensar nas garras pontiagudas de metal que são fixadas no solo apontando para o tronco de uma árvore, mais precisamente um mogno. À medida que ela cresce, ameaçada por uma situação não natural e agressiva, o tronco da árvore terá que se adaptar a esse constrangimento. Trata-se de Grande Budha, trabalho de Nelson Félix, que em 1985 instala, na floresta amazônica do Acre, seis garras de latão, determinado pelas coordenadas $10^{\circ} 07^{\prime}$ 49" S e $69^{\circ}$ 11' 11' W. Essa ação faz parte da obra Cruz na América, que inclui outras três ações entre os anos de 1985 e 2004 . O processo de crescimento de uma árvore é muito longo e aos olhos humanos pode ser quase imperceptível pelo tempo que demanda. Por meio dessa interferência, Félix provoca um desarranjo na natureza: o confronto e o encontro de duas matérias, uma orgânica e outra inorgânica, vegetal e mineral. Uma inconstante e mutável, a outra estável. Confronta também duas naturezas sensíveis: as barras de zinco e cobre, elementos naturais, porém já processados, em oposição à natureza virgem da árvore, com sua força dirigida ao seu crescimento e à sua perpetuação. A floresta amazônica é um organismo altamente dinâmico, onde distintas espécies convivem e se organizam. A ação de Félix propõe uma interferência em uma das centenas de milhares de árvores que formam a floresta. "Uma árvore, neste contexto, é um igual entre iguais; a floresta é uma imensidão cheia, construída por semelhantes ${ }^{3 "}$. A floresta é um conjunto de diferentes que constitui um só. $\bigcirc$ artista age e se retira logo depois de concluída a ação, entregando a matéria tradicionalmente escultórica para o tempo-duração e tempo clima, que vão tomar o lugar do artista e agir. Em uma floresta as árvores morrem e caem, enquanto outras nascem, ativando um ciclo dinâmico. Grande Budha deixa em aberto muitas perguntas: como a árvore vai responder a essa provocação? O metal rasgará o tronco da árvore em crescimento? Será possível voltar ao lugar exato passados muitos anos para acompanhar o desenrolar da ação? Como a floresta percebe essa intervenção? Todas essas perguntas que o trabalho propõe só encontram respostas no campo da imaginação e da suposição, e confirmam o poder da arte como campo de provocação e parceria compartilhada com a natureza, entendendo natureza como dimensão espacial e temporal. Os trabalhos do artista estão sempre acontecendo, não se limitam ao objeto esculpido e instaurado em alguma localidade, se expandem no tempo dilatado. A arte está no emaranhado do tempo e o pensamento é sobre o acontecimento. Félix sempre se refere a poesia como uma prática onde a certeza e a segurança não fazem parte, pois a poesia nunca sabe onde vai chegar. Assim como 
suas obras que acontecem no tempo da imprevi-

sibilidade, circularidade e instabilidade da natureza.

Em uma das cenas do vídeo Tônus, de Rodrigo Braga, vemos, de um lado, um braço sujo de lama apoiado ao chão, do outro, um caranguejo. Ambos estão interligados por uma pequena corda, que os ata e os impede de se afastarem um do outro. Eles lutam. O homem quer agarrar o bicho e o bicho quer morder o homem. A tensão é provocada pelo artista, um construtor de imagens, um interventor na natureza que provoca encontros entre seres, vivos e mortos, entre estados distintos da existência e de seu próprio corpo.
Estabeleço um paralelo entre esse trabalho, o Grande Budha de Nelson Félix a questão levantada por Serres anteriormente. Penso que este trabalho de Braga trata, primordialmente, dessa disputa. Além da cena da luta com o caranguejo, vemos também, no mesmo vídeo, o corpo do artista em várias outras ações: tentando empurrar uma rocha; rolando no chão movimentando duas árvores por duas longas cordas enroladas em sua cintura; deitado numa canoa semi naufragada com um peixe abatido em seu ventre; novamente atado por um braço e uma perna a um bode em um duelo de forças. Ouvimos sua respiração cansada do esforço físico e alguns

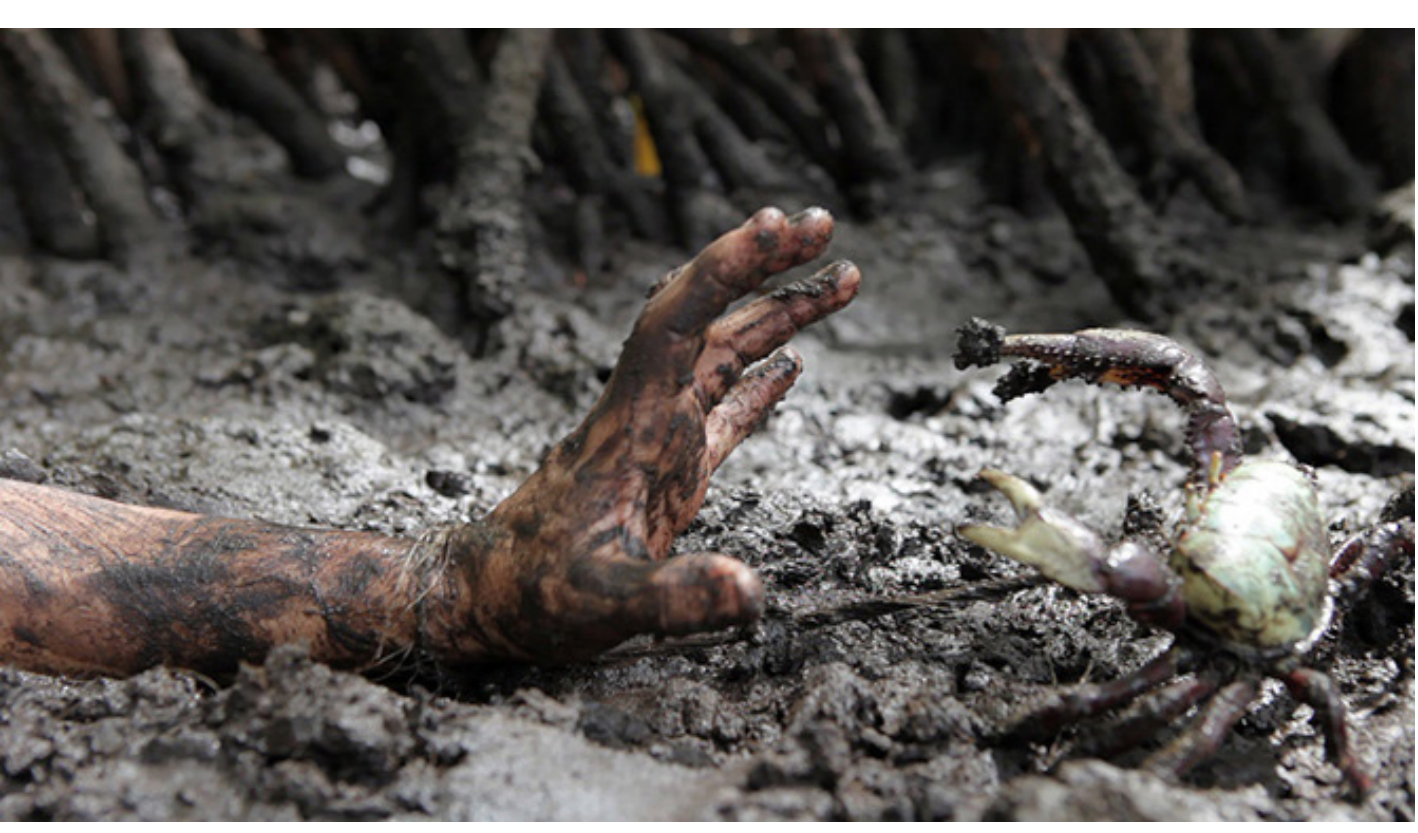

Fig. 1 - Rodrigo Braga, Tônus, 2012, frame de vídeo.

Fonte: https://www.rodrigobraga.com.br/Tonus gemidos de dor. Ouvimos também passarinhos, cigarras e o berro do bode. O bode cansa e se deita. Rodrigo também. O artista parece estar, com o uso de seu próprio corpo, em sua própria escala, propondo a pergunta: quem domina quem? Com esse trabalho em mente, procuro Rodrigo e o convido para uma conversa, que transcrevo aqui em formato entrevista. 


\section{AUTOR/A}

Então, Rodrigo, foi a partir do trabalho do Nelson Felix que eu comecei a pensar nessa parceira entre arte e natureza. Falo do Grande Budha. Ele ativou em mim uma série de questões. O que vai acontecer com o trabalho dele? Ele instala o trabalho ali e o deixa, sabendo que a natureza vai reagir. Por mais que ele não tenha essa preocupação, com o que vai acontecer, com o desenvolvimento, aquilo ali tem um desenvolvimento, vai acontecer alguma coisa. A Mesa que ele faz nos pampas, aquilo já cresceu, a esfera que ele deixa no mar, que em algum momento vai quebrar... Será que já quebrou, ou não? E aí eu comecei a pensar que não é mais uma questão de visualidade, trabalhar na natureza não é mais um olhar para a natureza, como a ideia de paisagem estética, é a ideia que se age com ela.

\section{RODRIGO BRAGA Isso me ajuda a pensar também meu próprio trabalho. Você está certa.}

\section{A Essa ideia tem sentido pra você?}

RB Tem sentido sim e amplia muito a discussão pra gente. Até porque você também, como fotógrafa, tem esse princípio do visual muito forte. Como eu, não só na fotografia mas na pintura lá atrás, que faz minha obra toda parecer pintura, no final das contas, imagem. Então, a gente ter essas outras visões mais ampliadas... evidentemente o trabalho é muito visual, mas como ela vai além, isso acho que o texto que vai falando também, né?

$[\ldots]$

A Quando você começou a pensar, a interagir com os ciclos da natureza, com os espaço da natureza? Eu sei que tem a ver com seus pais, não é?

Sim, tem a ver com formação sim. Eu vou falar sobre a minha experiencia, já que a pergunta é direta assim. Porque dentro da ciência e da biologia, tem muita naturalidade em alterar a natureza. Um veterinário ou um biólogo, se ele precisar estudar um animal, ele vai e mata o animal para estudar, sem 
frescuras e sem questões, porque para ele é um método científico que historicamente é estabelecido e aceito. Então, desde criança eu via meu pai, não nesses procedimentos específicos, embora ele já tenha feito, eu, enquanto criança, era um pequeno cientistazinho, fazendo pesquisas a ponto de pegar lagartixas, ou fazer enxertos com as plantas. Então essa operação na natureza já é algo da formação. [...] vem daí, não é Claudia. Mas também assim, sobre a observação, que é o que eu acho que te interessa, que o que a gente vive e vê de natureza é a natureza alterada eminentemente. Mesmo quando a gente vai a Amazônia, às vezes, nem sempre, o que você vai acessar lá são lugares trilhados, onde o homem já meteu a mão. [...] É pura observação do mundo. Na verdade, nós somos seres urbanos, duas pessoas que dialogamos com a natureza já alterada. Eu acho que é isso. E acho que essa discussão toda ecológica, que entrou pelo avesso na minha historia, porque meus pais são defensores da natureza, são ecologistas históricos, minha irmã se tornou ecologista e eu não, mas eu lido com a natureza. Então quando eu vou trabalhar, eu não assumo nenhum papel de ecologista, pelo contrário, sou criticado por ser malfeitor dos animais e da natureza. E aí é quase uma situação de matar o pai, né? Uma questão aí já mais ampla, da minha psique talvez, que eu vou descobrindo que minha matéria prima, Paulo Herkenhoff até fala isso, que eu não sou um artista que... meu tema central não é a natureza, é o homem. O que eu faço é da perspectiva da alteração, o título do livro era Ciclos Alterados. Basicamente, minha perspectiva é que onde o homem põe a mão na natureza dá merda, fica ruim. Em vários trabalhos que eu fiz tem um pouco disso, inclusive o Tônus, que é uma briga de força com um caranguejo. Quem fere quem?

\section{A Exatamente...}

RB Eu dei uma palestra há dez anos atrás, a convite da Glória Ferreira, com Nelson Félix.

\section{A Jura? Que lindo!}

RB Lindo, foi incrível. Foi no Museu da Vale, uma das palestras mais incríveis que eu já dei, ou melhor, que eu já estive, porque eu ainda era meio verdinho, foi umas das primeiras vezes mesmo saindo de Recife para viajar e dar palestra, peguei o Museu Vale, com o auditório e quinhentas pessoas! 
[...] Aí, depois de eu falar, Nelson falou e houve uma pergunta para o Nelson.

RB "Nelson, a arte avilta a vida ou a vida avilta a arte"? Aí o Nelson responde:

essa pergunta não é para mim, é para o Rodrigo! [risos], foi ótimo. É... é esse

lado de quem avilta quem... então a gente se supõe superior, controlador dessa

natureza, mas na hora H cria-se um musgo dentro de casa, na hora H deu um vento

e muda tudo, a chuva destruiu o que você fez e tal, então é essa briga de força que

está também no seu trabalho, dentro de um campo do incontrolável, não é? Do

imprevisível, que até é previsível de certa forma, mas é essa co-autoria com a

natureza que você fala. Eu acho um viés muito interessante do seu trabalho, e

inclusive nessa coisa dos rios flutuantes, ou voadores, que você toma um conceito

da biologia, da natureza em si. Já eu trabalhando lá com as mímeses, uma folha que parece um peixe, e que eu reproduzo isso. As inversões também de perspectiva.

A Sim, porque a mímesis vem da ideia da imagem, da fotografia, que também já toca em outro lugar.

RB Inclusive essa exposição "Agricultura da Imagem", que vai abrir em Recife e que estava aqui no BN-

DES, o curador toca muito nisso, nas mímeses. O título é Agricultura da Imagem, nesse sentido que o Jeff Wall falava do fotografo agricultor.

A Eu gosto muito dessa ideia, do fotógrafo que vai criar a imagem.

RB É aquele que vai criar uma situação para fotografar.

[... 
Tem uma coisa que eu fico pensando também, que no próprio Labverde, essa residência que vc fez e que eu vou fazer, tem uma proposta, um tipo de slogan que é algo "como a arte effects a natureza?". Eles não usam o termo afetar, eles usam o termo effect, como se fosse um efeito, né? Assim como uma coisa cria efeito na outra. E aí eu fico pensando nesse lugar do artista, no lugar da proposta com a natureza, dessa natureza alterada, dessa natureza dominada... Você acha que a gente tem um lugar de defensor? A gente tem que ter esse lugar? Eu sei que tem alguns artistas que acham que sim, que a arte tem uma proposta ativista, de defender causas, etc. Eu não sou exatamente dessa praia, mas fico pensando o quanto isso ecoa pra você, se você acha que o artista ou a arte tem esse lugar de defesa do mundo, de defesa da natureza, dos gêneros, das raças...

RB: Isso é uma coisa que acabei pensando muito, dentro dessa forma de trabalhar que traz isso porque é essa coisa, filho de biólogos, ecologistas, irmã ecologista, cunhado ecologista...

A Você está cercado de ecologistas...

$\mathrm{RB}$

Sim, e aí é esperado de mim uma postura. Mas desde cedo, enquanto eu fui fazer o Fantasia de Compensação, aquele trabalho do cachorro há anos atrás, há uma conversa com os pais. E é curioso porque eles nunca foram contrários, sobretudo meu pai gosta de problematizar e debater tudo. Essaé uma questão que volta e meia me acontece e me ocorre, de me perguntar: e a ética disso? E o meu papel nisso tudo? Sou um cara que lida também com públicos, e lidar com as pessoas é ouvir as pessoas também. E é também ser confrontado, e o tempo todo eu sou confrontado nessa perspectiva da ética também, né? A

Você acha que isso ocorre principalmente pelo trabalho do cachorro?

RB Principalmente, obviamente. Mas...

Claudia Tavares, Entrevista com Rodrigo Braga 


\section{A É o seu trabalho mais forte, não?}

RB Sim, o mais forte. Mas olha, tem gente que não conhece o do cachorro e vem me questionar por outros. Bizarramente assim, as vezes trabalhos que são até fofos a parentemente, me causam problema. Tem um que usa penas de araras e papagaios, que causa problema.

\section{A Qual tipo de problema? Tipo, você matou a arara pra pegar a pena?}

$\mathrm{RB}$ Isso, de onde veio? Esse trabalho deu

A Aívocê que comprou ali...

RB Comprei ali não! Vai explicar o caminho que você faz, que está muito dentro do meu trabalho, que nada vem fácil assim... então essa discussão sobre meu papel nisso tudo passa mas eu mando meio 'pras cucuias'. Não é que eu desconsidere, mas eu acho mais importante nossa liberdade de criação.
A Poisé, porque eu penso que o lugar do artista não é o lugar do cidadão...

RB É mesmo, cidadão?

A Sim, a ideia de pensar no Sebastião Salgado, por exemplo, que vem com um papel messiânico de cidadão que deve salvar o mundo através das suas fotografias. Vou salvar o mundo, vou salvar a natureza...

RB Tem okrajcberg...

A O Krajcbergtalveztambém..

RB É que ele sente a dor da natureza, mas é diferente porque tem a história da família dele, de violência a família, como fugitivo de guerra ele mesmo, uma família que foi queimada. Então ver a mata sendo queimada é outra entrada pro trabaIho. Mas ambos têm esse sentido de dever. 
A Mas esse lugar de dever, eu não acho que a gente tem que assumir esse lugar. Eu acho que a arte toca, provoca, ela te coloca num lugar mais confortável ou menos, mas...

RB É aquela velha questão, Claudia, eu acho que a gente propõe. Acho que nosso maior tesão de trabalhar com arte e fazer nossas ideias é propor. E essas questões ecoam na gente às vezes mais do que a gente imagina. Eu deixei de comer carne no meio de processo de trabalho, junto a vários outros motivos. Faz dez anos que eu não como animais grandes, eu como peixe, frutos do mar. Mesmo assim há umas escolhas dentro disso. Mas eu já dei palestras sem citar isso e já tive depoimento de gente que deixou de comer carne depois de ver uma palestra minha. Então isso ecoa de uma forma inesperada as vezes.

A Acho que muito mais do que no grito, do que na bandeira, né?

RB Eu acho. Porque aí que tá, a questão que aonde a gente opera, que é muito mais poderoso, é nesse ambiente sutil e subliminar. As vezes a gente toca mais pelo sentimento do que fazendo discurso.
Segundo alguns estudos ainda não totalmente reconhecidos pela ciência enquanto instituição global, estamos hoje na era do Antropoceno, a era geológica que sucede ao Holoceno. Como característica principal do conceito de Antropoceno, a humanidade enquanto agente vem causando radicais mudanças sistemáticas na natureza, em velocidade crescente, no tocante ao clima, ao solo, à vegetação, à água e à vida no planeta. Uma nova camada geológica é atribuída à presença de polímeros plásticos achados nas rochas, o que registra comprovadamente a ação humana na Terra. É uma nova era que se inicia em estado de alerta, causando risco ao futuro do nosso planeta e consequentemente à vida humana na terra. Michel Serres não se refere diretamente ao conceito de Antropoceno, na escrita de seu livro, mas já atenta para essa alteração no curso do planeta. É com essa ideia de fundo que venho pensando, mesmo sem utilizar o termo, em relacionar arte e natureza. Se o planeta muda, a vida muda junto e, consequentemente, a maneira de fazer e pensar arte é afetada por essa mudança. Encontro base, a partir do livro de Serres, para pensar numa mudança de atitude artística em relação à natureza. No entanto, os artistas escolhidos aqui não se colocam como agentes ativistas de uma bandeira ecológica. Entendo a contaminação da arte pelas ciências como uma ampliação do escopo de pesquisa, não necessariamente como ponto de partida 
para uma atuação artística, mas como um campo ampliado de conceitos estéticos e científicos. Tanto a arte como a ciência não buscam a verdade, mas sim as evidências e possibilidades, embora a ciência lide com resultados concretos e gráficos demonstrativos e a arte lide com a sensibilização.

Acredito que é no gesto artístico, nos deslocamentos propostos, nas provocações sutis que reside a força da arte contemporânea. A arte afeta, não procura efeito. Sua metodologia é distinta da ciência, embora possa se alimentar de dados científicos. Sua natureza é política em si, independente de bandeiras levantadas. Não tem a função de transmitir mensagens, nem de atingir resultados previamente estudados, deixa isso para outros campos de conhecimento e atuação. A meu ver a arte de Rodrigo Braga conjuga com esse pensamento, e o artista, em um texto que escreve sobre a Amazônia, provoca:

Quem sabe artistas que versam experiências ambientais não teriam um senso estético mais voltado a sentidos um tanto ou quanto mais sutis do que apenas o inicial prazer da satisfação retiniana? Ou seja, seria possível que os artistas e as artistas se seduzissem não tão somente pelo visual ou o analítico, mas que explorassem sensações mais abrangentes, como quem quer adentrar com a pele, sentir os odores e sabores, ouvir os pequenos seres, estar e pensar a sós, sob um tempo dilatado, sobre todas as evocações sensíveis que um igarapé proporciona? As terras extremamente irrigadas, os vapores, as chuvas densas, a água por si, enfim, além de um grande berçário, poderiam ser metáforas para a gestação geral de seres, ou para a gestação de ideias, de criação de mundos como princípio? ${ }^{4}<$

NOTAS

1 SERRES, Michel. O contrato natural. Lisboa: Instituto Piaget, 1990.

2 TAVARES, Claudia. Um jardim em Floresta, a natureza como sujeito. Revista Concinittas. Volume 20, número 35, 2019. Disponível em: https://doi.org/10. 12957/concinnitas.2019.44875 3 http://nelsonfelix.com.br/obras/cruz-na-america/ 4 Braga, Rodrigo - Amazônia lugar placenta em https://www.revistacontinente.com.br/edicoes/212/amazonia--lugar-placenta 


\section{REFERÊNCIAS BIBLIOGRAFICAS}

BRAGA, Rodrigo. Amazônia lugar placenta em https://www.revistacontinente.com.br/edicoes/212/amazonia--lugar-placenta

SERRES, Michel. O contrato natural. Lisboa: Instituto Piaget, 1990.

TAVARES, Claudia. Um jardim em Floresta, a natureza como sujeito. Revista Concinittas. V. 20, N. 35, 2019. Disponível em: https://doi.org/10.12957/concinnitas.2019.44875 